$\underline{\text { www.pubvet.com.br }}$

\title{
Aspectos epidemiológicos da cinomose em cães atendidos em um Hospital Veterinário no período de 2011 a 2013
}

\author{
Leana Bruna Salomão de Brito $^{1}$, Oaiana Trindade Pereira ${ }^{1}$, Paulo André Choairy \\ Oliveira $^{2}$, Tiago da Silva Teófilo ${ }^{3}$, Renata Mondego Oliveira ${ }^{4}$, Ana Lúcia Abreu Silva ${ }^{5}$, \\ Mylena Andréa Oliveira Torres ${ }^{5 *}$
}

${ }^{1}$ Médica Veterinária pela Universidade Estadual do Maranhão, São Luís, Maranhão, Brasil.

${ }^{2}$ Engenheiro de Pesca pela Universidade Estadual do Maranhão, São Luís, Maranhão, Brasil.

${ }^{3}$ Departamento de Zootecnia - Universidade Estadual do Maranhão, São Luís, Maranhão, Brasil.

${ }^{4}$ Mestre em Ciência Animal, Universidade Estadual do Maranhão, São Luís, Maranhão, Brasil.

${ }^{5}$ Departamento de Patologia, Medicina Veterinária, Universidade Estadual do Maranhão, São Luís, Maranhão, Brasil.

*Autor para correspondência, E-mail: mylena_torres@yahoo.com.br

\begin{abstract}
RESUMO. O objetivo desse estudo foi avaliar os aspectos epidemiológicos da cinomose canina em animais atendidos no Hospital Veterinário da Universidade Estadual do Maranhão. Foi feito levantamento de dados de 10200 fichas clínicas de cães atendidos no período de janeiro de 2011 a dezembro de 2013, à procura de casos suspeitos e confirmados. 461 animais foram diagnosticados com a doença e 202 foram considerados suspeitos, em um total de 663 casos de cinomose. O percentual de machos afetados foi de 53,4\% e de fêmeas, 46,6\%. Com relação à idade, a faixa etária mais afetada foi entre $0-5$ anos, totalizando $89,6 \%$, e a menos afetada entre 11 a 17 anos (2,3\%). Quanto à raça, as mais predominantes foram os animais sem raça definida $(65,5 \%)$, Poodle $(12,5 \%)$, Pinscher $(8,75 \%)$ e Pitbull $(2,9 \%)$. A doença ocorreu em todos os meses do ano, com maior prevalência entre os meses de julho a setembro e menor prevalência em abril e dezembro. Houve uma alta prevalência de cinomose canina em comparação ao número de cães atendidos no hospital veterinário, o que sustenta a importância da aplicação de medidas de prevenção e controle da doença.
\end{abstract}

Palavras chave: Vírus, epidemiologia, caninos.

\section{Canine distemper prevalence in dogs attended at the Veterinary Hospital from 2001 to 2013}

\begin{abstract}
The aim of this study was to evaluate the epidemiological aspects of canine distemper in animals attended at the Veterinary Hospital of the State University of Maranhão. Data collection of 10200 medical records of dogs was made, attended from January 2011 to December 2013, looking for suspected and confirmed cases. 461 animals were diagnosed with the disease and 202 were considered suspects, in a total of 663 cases of distemper. The percentage of affected males was $53.4 \%$ and females $46.6 \%$. Regarding to age, the most affected age group was between 0-5 years, totaling $89.59 \%$, and the least affected group, between 11 to 17 years (2.3\%). Regarding to the breed, the most prevalent breeds were mongrel animals $(65.5 \%)$, Poodle (12.5\%), Pinscher (8.7\%) and Pitbull (2.9\%). The disease occurred all year long, with the highest prevalence in the months from July to September and lower prevalence in April and December. There was a high prevalence of canine distemper in comparison to the number of dogs attended at the veterinary hospital, which supports the importance of implementing measures to prevent and control the disease.
\end{abstract}

Keywords: Virus, epidemiology, canine. 


\section{Introdução}

A cinomose canina é uma enfermidade infectocontagiosa causada por um vírus da família Paramyxovirus, gênero Morbilivirus; que afeta principalmente cães e outros carnívoros. Os animais mais susceptíveis são cães jovens, entre quatro e seis meses de idade (Nascimento, 2009).

Não existem fatores predisponentes para o estabelecimento da doença, tais como sexo, idade ou raça (Gama et al., 2005). No entanto, alguns trabalhos enfatizam que a sua incidência é maior no período em que há diminuição da taxa de anticorpos maternos, que ocorre entre os 60 e 90 dias de idade. Animais de todas as idades podem ser acometidos, principalmente devido a falhas imunológicas, contato com o vírus ou ausência de vacinação (Quinn et al., 2005).

A transmissão do vírus ocorre principalmente por meio de aerossóis, alimentos, água e fômites contaminados, sendo eliminadas por vários meses no ambiente pelas urinas, fezes, saliva e secreções (nasais, conjuntivais e lacrimais). Após a infecção, o período de incubação é de aproximadamente três a sete dias (Catroxo, 2003).

Os sinais clínicos da cinomose variam de acordo com a espécie, cepa infectante, condições ambientais, idade, estado geral e imunológico do indivíduo (Gomes et al., 2007). Por se tratar de doença multissistêmica, as manifestações clínicas incluem alterações respiratórias, gastrintestinais, dermatológicas e do sistema nervoso central (Monteiro et al., 2010).

A fase neurológica é considerada o estágio mais avançado da doença, e pode ser caracterizada por alterações de comportamento, apatia, ataxia, paraplegia, tetraplegia, sintomas cerebelares (tremores de cabeça e hipermetria), paralisia de mandíbula, bexiga e do reto, vocalização similar à do estado de dor, mioclonias, convulsões e coma (Amude et al., 2006).

Visando alertar a população a respeito do grande número de animais infectados pelo vírus, este trabalho teve como objetivo realizar um estudo epidemiológico de casos de cinomose canina.

\section{Material e Métodos}

Foi feito o levantamento de dados das fichas clínicas de cães atendidos no Hospital Veterinário "Francisco Edilberto Uchoa Lopes" da Universidade Estadual do Maranhão (HOVETUEMA), no período de janeiro de 2011 a dezembro de 2013, à procura de casos suspeitos e confirmados. Foram analisadas também a prevalência das fases da doença, o método de diagnóstico e as seguintes variáveis epidemiológicas: raça, sexo e idade.

\section{Análise dos dados}

Os dados coletados foram tabulados no programa Microsoft Office Excel 2010, utilizando-se cálculos e construções de gráficos, para posterior análise estatística descritiva simples. A análise descritiva envolveu questões básicas sobre a determinação das características dos indivíduos afetados pelo dano (por sexo, faixa etária, ocupação etc.). As características que definem o período de tempo no qual os indivíduos foram afetados foram determinadas com as respectivas frequências do evento por ano, mês, semana ou outra unidade de tempo, e computados para verificar a variação temporal do evento, seja ela secular, estacional ou de outra natureza.

\section{Resultados e Discussão}

Nos três anos analisados foram atendidos um total de 10200 animais, sendo 3.224 animais no ano de 2011, 3.633 em 2012 e 3.343 em 2013 (Tabela 1).

Tabela 1. Número total de animais suspeitos e positivos para cinomose canina atendidos no HV-UEMA entre os anos de 2011 a 2013.

\begin{tabular}{lccc}
\hline Ano & Animais positivos & Animais suspeitos & Total \\
\hline 2011 & 174 & 32 & 206 \\
2012 & 149 & 107 & 256 \\
2013 & 138 & 63 & 201 \\
Total & 461 & 202 & 663 \\
\hline
\end{tabular}

Com relação ao sexo, o total de machos suspeitos e positivos para cinomose atendidos no período estudado foi de $354(53,4 \%)$, e o de fêmeas, 309 (46,6\%). Em estudo realizado por Barbosa \& Passos (2008) foi encontrado resultado semelhante, um percentual de $55,1 \%$ de machos 
em relação ao número total de fêmeas $(48,9 \%)$. A predominância de idade também foi observada e a faixa etária de maior ocorrência foi entre 0 a 5 anos, em um total de 594 casos $(89,6 \%)$, seguido pelo intervalo de 5 a 11 anos, com 54 casos $(8,2 \%)$. O período de menor ocorrência entre 11 a 17 anos, com 15 casos (2,3\%). Barbosa \& Passos (2008) observaram uma maior predominância da doença em cães na faixa etária de 0 a 5 anos, totalizando $73,4 \%$ dos casos atendidos.

Dentre as faixas etárias, os filhotes são considerados o grupo que menos desenvolvem distúrbios neurológicos. Por isso, conseguem sobreviver à uma infecção inicial e posteriormente desenvolver imunidade parcial ao vírus. No entanto, esses cães correm o risco de manifestarem a doença no sistema nervoso central quando adultos (Fenner et al., 2004).

Frade \& Dantas (2011), em estudo semelhante, verificaram que, dos 41 casos estudados, 58,54\% dos cães tinham até 1 ano de idade, $39,3 \%$ entre 1 e 9 anos e 2,44\% eram acima de 10 anos de idade. Animais de todas as idades podem ser infectados, mas filhotes são mais suscetíveis, especialmente quando há diminuição da imunidade conferida pela mãe (Appel \& Summers, 1995). A idade média observada dos animais acometidos por cinomose em estudos feitos por Santos et al. (2012) foi de 7 anos.

Quanto à prevalência das fases da doença, o total de animais na fase respiratória foi de 63 (9,5\%), 77 animais na fase dermatológica $(11,6 \%)$ e 69 na fase gastrointestinal $(10,4 \%)$. A maior prevalência foi de animais na fase neurológica, totalizando 454 casos $(68,5 \%)$.

Em estudos feitos por Frade \& Dantas (2011), os sinais clínicos observados foram bastante variáveis, afetando um ou mais sistemas. Ocorreram principalmente alterações neurológicas, digestórias, respiratórias, oftalmológicas e cutâneas. Santos et al. (2012) observou inapetência, anorexia, diarréia, vômito, secreção ocular e nasal, sendo os sinais clínicos sistêmicos mais frequentes.

Os cães infectados pelo vírus da cinomose (VCC) podem manifestar uma combinação de lesões respiratórias, gastrintestinais, cutâneas e neurológicas que podem ocorrer em sequência ou simultaneamente (Gröne et al., 2003, Koutinas et al., 2002).

Os principais sinais neurológicos analisados no nosso estudo foram: mioclonias ataxia, vocalização e convulsões, com prevalências de $47 \%$, 28,9\%, $16,7 \%$ e 7,4\%, respectivamente. Resultados semelhantes foram observados por Santos et al. (2012) que observaram a ocorrência dos mesmos sinais neurológicos. Silva et al. (2007) também diagnosticaram a mioclonia como um sinal neurológico presente em $38,4 \%$ dos casos de cinomose avaliados, e relatam que a doença sempre deve ser considerada como primeira opção como diagnóstico diferencial em animais que apresentem este sinal. A forma neurológica da cinomose é caracterizada por uma grande variedade de sinais clínicos, em que os cães podem apresentar um único sinal clínico ou uma combinação deles (Silva et al., 2007).

Em áreas onde o VCC é endêmico, é importante um diagnóstico diferencial para cães com disfunção neurológica, independente do tipo, extensão e natureza da doença nervosa (Amude et al., 2007).

Dentre as raças atendidas, ocorreram 434 $(65,5 \%)$ casos em cães sem raça definida (SRD), seguida por 83 casos $(12,5 \%)$ na raça Poodle, 58 $(8,7 \%)$ em Pinscher e 19 (2,9\%) em Pitbull. Frade \& Dantas (2011) constataram que $74 \%$ dos casos foram em cães SRD, seguida das raças Poodle e Pinscher (8\%), Cocker Spaniel (6\%), Boxer e Beagle (2\%). A maior ocorrência em cães SRD pode ser explicada pela população animal atendida no $\mathrm{HV}$, predominantemente composta por cães SRD, pois cães de todas as raças são suscetíveis à infecção pelo vírus (Latha et al., 2007). Barbosa \& Passos (2008) observaram que a prevalência da doença em cães SRD foi de 32\%, seguido da raça Poodle (13\%) e Cocker (4\%). Santos et al. (2012) relataram que a maior frequência de cães positivos para cinomose foram em cães de raças puras $(57,7 \%)$, sendo a raça Poodle a mais predominante $(10,7 \%)$ seguida dos cães SRD (42,3\%), discordando dos estudos acima citados.

Dos animais avaliados, os que não eram vacinados contra nenhuma doença constituíam maior percentual, com $49 \%$ dos casos, totalizando 323 animais; 247 eram vacinados apenas com a vacina antirrábica (37\%) e apenas 93 animais 
(14\%) eram vacinados com a vacina poliviral, porém ou estas estavam atrasadas ou incompletas.

Frade \& Dantas (2011) relataram que em apenas 25 casos de cinomose do total avaliado foi informado o estado vacinal dos animais. Desses, 22 não haviam sido vacinados e os demais tinham vacinação incompleta ou não receberam reforço vacinal anual. De 22 casos clínicos suspeitos de cinomose, $86,4 \%$ dos animais não eram vacinados. Já Santos et. al. (2012) relataram que, dos animais atendidos no Hospital Veterinário de Uberaba (MG), no período de janeiro de 2008 a julho de $2012,45,6 \%$ não eram vacinados para cinomose, $35,6 \%$ estavam com a vacinação incompleta e $18,8 \%$ apresentavam vacinação completa. A única medida para controle da doença é a vacinação. Latha et al. (2007) ainda sugerem que a vacinação seguida por regulares reforços anuais seria efetiva na proteção dos cães contra a doença, reduzindo significativamente os riscos de infecção. No período estudado, a doença foi diagnosticada apenas através de sintomatologia clínica em 410 cães, o que corresponde a $62 \%$ do total; 61 casos foram diagnosticados laboratorialmente (9\%), e 192 casos tiveram diagnóstico clínico e laboratorial (29\%). Em estudos descritos por Santos et al. (2012) foram diagnosticados antígenos do vírus da cinomose em 19,9\% dos cães avaliados.

\section{Diagnóstico}

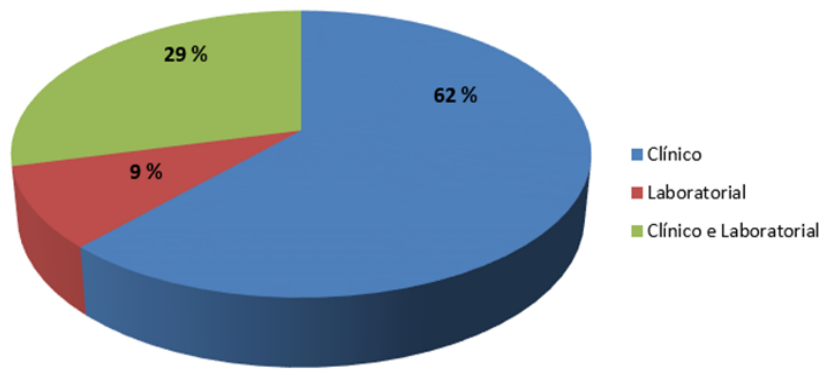

Figura 1. Formas de diagnóstico da cinomose em cães atendidos no Hospital Veterinário da UEMA, no período de 2011 a 2013.

Os meses de maior ocorrência do vírus foram setembro, agosto e julho, respectivamente. De acordo com Santos et al. (2012) observou-se sazonalidade na ocorrência da cinomose, com maior frequência entre os meses de abril e setembro, correspondendo a 63,8\% dos casos.
Frade \& Dantas (2011) relataram que a doença ocorreu em todos os meses do ano, com maior ocorrência nos meses de abril, maio e julho, com $16 \%$ cada, que correspondem aos meses do ano com as menores temperaturas. O VCC é resistente ao frio e pode sobreviver por um longo período de tempo sob essas condições, ocorrendo à disseminação da doença principalmente no inverno (Latha et al., 2007). Lima (2007) também demonstrou a ocorrência da doença em períodos de temperaturas mais amenas e de maior umidade, com maior número de casos nos meses de maio a agosto.

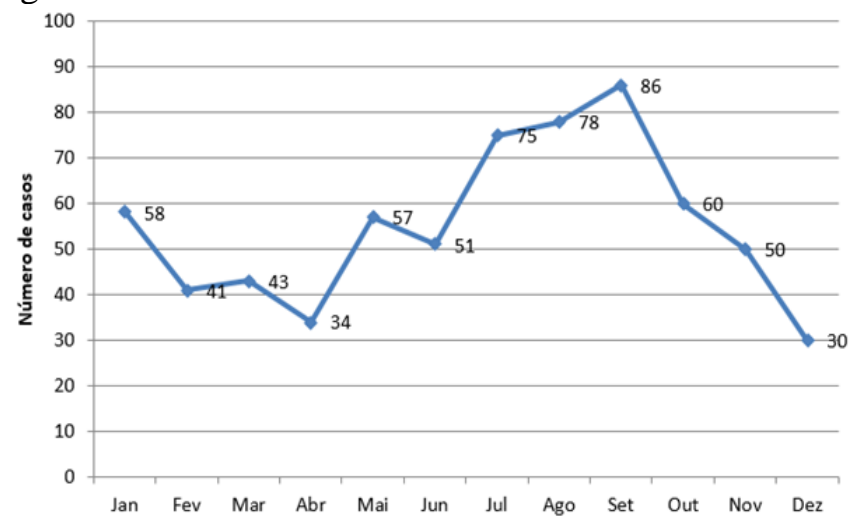

Figura 2. Distribuição mensal da cinomose de cães atendidos no HOVET-UEMA nos anos de 2011 a 2013.

\section{Conclusão}

A alta prevalência da cinomose canina em filhotes não vacinados, independente de sexo e da época do ano, sustenta a importância da aplicação de medidas mais eficazes de prevenção e controle da doença.

\section{Referências Bibliográficas}

Amude, A. M., Alfieri, A. A. \& Alfieri, A. F. (2007). Clinicopathological findings in dogs with distemper encephalomyelitis presented without characteristic signs of the disease. Research in Veterinary Science, 82, 416-422.

Amude, A. M., Carvalho, G. A., Balarin, A. R. S., Arias, M. V. B., Reis, A. C. F., Alfieri, A. A. \& Alfieri, A. F. (2006). Encefalomielite pelo vírus da cinomose canina em cães sem sinais sistêmicos da doença-estudos preliminares em três casos. Clínica Veterinária, 60, 60-66.

Appel, M. J. G. \& Summers, B. A. (1995). Pathogenicity of morbilliviruses for terrestrial 
carnivores. Veterinary Microbiology, 44, 187191.

Barbosa, J. M. \& Passos, R. F. B. (2008). Análise dos casos de cinomose no H.V. Ensaios $e$ Ciência: Ciências Biológicas, Agrárias e da Saúde, 12, 1-10.

Catroxo, M. H. B. (2003). Cinomose canina. Arquivo do Instituto Biológico de São Paulo, 65, 1-2.

Fenner, W. R., Ettinger, S. \& Feldman, E. (2004). Doenças do cérebro. Tratado de Medicina Interna Veterinária: doenças do cão e do gato, 1, 586-638.

Frade, M. T. \& Dantas, A. C. M. (2011). Aspectos epidemiológicos, clínicos e patológicos da cinomose canina. VIII Congresso de Iniciação Científica. Universidade Federal de Campina Grande, Universidade Federal de Campina Grande, Patos.

Gama, F. G. V., Nishimori, C. T., Sobreira, M. R. \& Santana, A. E. (2005). Caracteres físicoquímicos e citológicos do liquor de cães em diferentes fases da cinomose. Ciência Rural, 35, 596-601.

Gomes, M. S., Cubas, Z. S., Silva, J. C. R. \& Catão-Dias, J. L. (2007). Carnívora-Canidae (lobo guará, cachorro do mato, raposa do campo). Roca, São Paulo.

Gröne, A., Engelhardt, P. \& Zurbriggen, A. (2003). Canine distemper virus infection: proliferation of canine footpad keratinocytes. Veterinary Pathology Online, 40, 574-578.

Koutinas, A. F., Polizopoulou, Z., Baumgaertner, W., Lekkas, S. \& Kontos, V. (2002). Relation of clinical signs to pathological changes in 19 cases of canine distemper encephalomyelitis. Journal of Comparative Pathology, 126, 47-56.

Latha, D., Srinivasan, S. R., Thirunavukkarasu, P. S., Gunaselan, L., Ramadass, P. \& Narayanan,
R. B. (2007). Assessment of canine distemper virus infection in vaccinated and unvaccinated dogs. Indian Journal of Biotechnology, 6, 3540.

Monteiro, M. V. B., Santos, M. P., Temistocles, C., Costa, C., Whiteman, C. W. \& Monteiro, F. O. B. (2010). Cinomose canina nos animais domésticos e silvestres. Revista de Ciências Agrárias, 53, 216-223.

Nascimento, D. N. S. (2009). Cinomose CaninaRevisão de Literatura. Santa Maria.

Quinn, P. J., Markey, B. K., Carter, M. E., Donnelly, W. J. \& Leonard, F. C. (2005). Microbiologia Veterinária e Doenças Infecciosas. Artmed, Porto Alegre.

Santos, J. P., Borges, C. E. F., Locce, C. C., Junior, Á. F., Bittar, E. R., Ayres, D. R. \& Bittar, J. F. F. (2012). Estudo retrospectivo de cães positivos para cinomose, em ensaio imunocromatográfico, atendidos no hospital veterinário de Uberaba-MG. Veterinária Notícias, 18, 31-36.

Silva, M. C., Fighera, R. A., Juliana, S., Graça, D. L., Kommers, G. D., Irigoyen, L. F. \& Barros, C. S. L. (2007). Aspectos clinicopatológicos de 620 casos neurológicos de cinomose em cães: Clinicopathological features in 620 neurological cases of canine distemper. Pesquisa Veterinária Brasileira, 27, 215-220.

Recebido em Março 25, 2016

Aceito em Abril 22, 2016

License information: This is an open-access article distributed under the terms of the Creative Commons Attribution License, which permits unrestricted use, distribution, and reproduction in any medium, provided the original work is properly cited 